\title{
Respons perilaku sapi bali terhadap lalat vektor dan pengganggu di ladang penggembalaan lahan kering tropis
}

\author{
Aji Winarso $\circledast^{1, *}$, Bradley J. O’Hagan ${ }^{2}$ \\ ${ }^{1}$ Fakultas Kedokteran Hewan, Universitas Nusa Cendana, Kupang, Nusa Tenggara Timur \\ ${ }^{2}$ Australian Volunteers International
}

\begin{abstract}
ABSTRAK: Infestasi lalat penghisap darah dan keberadaan lalat pengganggu sangat merugikan bila dilihat dari potensi vektor maupun cekaman yang ditimbulkan terhadap sapi. Perubahan perilaku akibat gangguan lalat menimbulkan kerugian energi, berkurangnya waktu makan, dan hal ini dapat menurunkan produktivitas ternak. Penelitian ini merupakan penelitian survey yang bertujuan menggambarkan perilaku sapi Bali yang diinfestasi lalat penghisap darah dan dikitari lalat pengganggu. Penelitian dilakukan terhadap 8 ekor sapi yang digembalakan di padang gembala umum di Dusun Matani, Desa Penfui Timur, Kecamatan Kupang Tengah, Kabupaten Kupang melalui observasi keberadaan lalat pengganggu yang hinggap pada permukaan tubuh sapi. Selanjutnya perilaku sapi Bali yang dihinggapi lalat-lalat tersebut diamati pada saat sapi dalam kondisi istirahat $(\mathrm{n}=4)$ maupun sedang merumput $(\mathrm{n}=4)$. Data diolah dan ditampilkan secara statistik deskriptif. Hasil penelitian menunjukkan bahwa respon sapi terhadap keberadaan lalat pengganggu sebagai gejala fly worry, secara signifikan mengalihkan perhatian ternak selama aktivitas merumput, dan tidak terlalu nyata selama ternak berbaring ruminasi.
\end{abstract}

Kata kunci:

Bos sondaicus, fly worry, semi arid, Timor.

\section{- PENDAHULUAN}

Peternakan sapi di Kabupaten Kupang pada umumnya dikelola dengan sistem semi-intensif. Sepanjang musim penghujan, ketika rumput tersedia melimpah, sebagian besar ternak sapi digembalakan selama siang hari dan pulang ke kandang pada petang harinya. Selama digembalakan, sapi sangat rentan terpapar lalat penghisap darah dan lalat pengganggu lainnya.

Keberadaan lalat pengganggu yang berpotensi sebagai vektor penyakit masih kurang diperhatikan oleh peternak skala kecil baik di Nusa Tenggara Timur maupun di wilayah lain di Indonesia. Sementara itu, infestasi lalat penghisap darah dan keberadaan lalat pengganggu sangat merugikan bila dilihat dari potensi vektor maupun cekaman yang ditimbulkan terhadap sapi. World Association for the Advancement of Veterinary Parasitology (WAAVP) menggunakan istilah "fly worry" untuk menggambarkan perubahan perilaku akibat gangguan lalat (Holdsworth et al., 2006). Perubahan perilaku akibat gangguan lalat menimbulkan kerugian energi, berkurangnya waktu makan, dan sehingga dapat menurunkan produktivitas ternak. Penelitian ini bertujuan menggambarkan perilaku sapi Bali yang diinfestasi lalat penghisap darah dan dikitari lalat pengganggu.

\section{- MATERI DAN METODE}

Penelitian survey dilakukan pada 8 ekor sapi Bali yang digembalakan di padang gembala umum di Dusun Matani, Desa Penfui Timur, Kecamatan Kupang Tengah, Kabupaten
Kupang pada bulan Maret 2018. Penelitian dilakukan dengan mengobservasi keberadaan lalat pengganggu yang landing pada permukaan tubuh sapi. Pengamatan dilakukan 2 kali pada sore hari dengan jeda 7 hari (10 dan 17 Maret 2018). Selanjutnya perilaku sapi Bali yang dihinggapi lalatlalat tersebut diamati pada saat sapi rebah atau istirahat /ruminasi $(n=4)$ maupun sedang berdiri merumput $(n=4)$. Data diolah dan ditampilkan sebagai statistik deskriptif.

\section{- HASIL DAN PEMBAHASAN}

Infestasi lalat penghisap darah pada sapi Bali dalam penelitian ini didominasi oleh lalat sumba atau lalat kutu dari genus Hippobosca (Gambar 1). Genus Hippobosca memiliki bentuk tubuh yang pipih dorso-ventral, dengan kaki dan sayap yang relatif besar (Zajac \& Conboy, 2012). Pulau Timor merupakan satu di antara beberapa daerah habitat endemik bagi lalat Hippobosca (Hadi \& Soviana 2010).

Perilaku sapi dilaporkan mengalami perubahan oleh adanya gangguan lalat (fly worry) diakibatkan oleh aktivitas lalat ketika mencari makan (Mauldin \& Peters-Kennedy, 2016). Lalat penggigit (biting flies) memberikan rasa sakit (atau gatal) pada area gigitan, sedangkan lalat yang bukan penggigit (non-biting flies) mengganggu dengan mengitari nostril dan mata dimana mereka makan air mata dan lele-

Diterima: 13-03-2019 | Direvisi: 15-04-2019 | Disetujui: 21-04-2019

(C) 2019 CC-BY-SA. Ini adalah artikel Open Access yang didistribusikan berdasarkan ketentuan dari Creative Commons Attribution ShareAlike 4.0 International License (https://creativecommons.org/licenses/by-sa/4.0/). 
ran/cairan lainnya (Mauldin \& Peters-Kennedy, 2016). Lalat juga mengganggu karena dengungan suaranya.

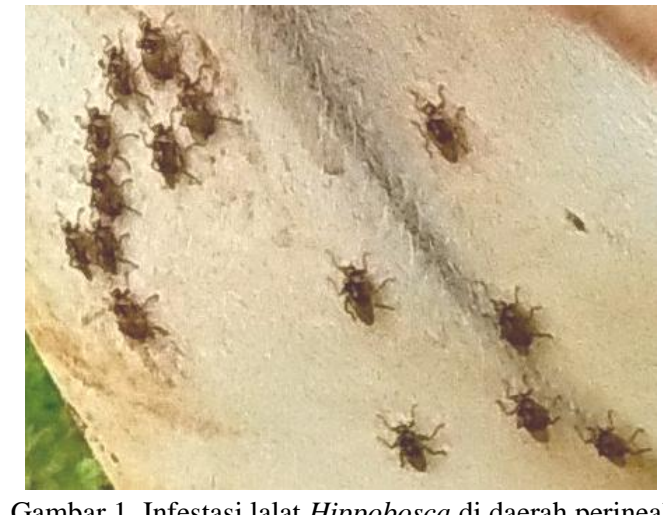

Penelitian ini mendapatkan data bahwa aktivitas sapi yang menunjukkan perilaku sebagai reaksi terhadap gangguan lalat lebih banyak terjadi selama sapi merumput (Tabel 1). Tercatat perbedaan tertinggi untuk frekuensi ekspresi perilaku ketika sapi berdiri (merumput) dan rebahan (istirahat) adalah mengibaskan telinga dan mengibaskan ekor. Kedua ekspresi tersebut juga merupakan yang tertinggi dari semua ekspresi perilaku yang diamati.

Tabel 1 Frekuensi ekspresi perilaku akibat gangguan lalat

\begin{tabular}{|lcc|}
\hline \multirow{2}{*}{ Ekspresi gerakan } & \multicolumn{2}{c|}{ Frekuensi (kali/menit) } \\
\cline { 2 - 3 } & $\begin{array}{c}\text { Merumput } \\
(\mathbf{n}=\mathbf{4})\end{array}$ & $\begin{array}{c}\text { Istirahat } \\
(\mathbf{n}=\mathbf{4})\end{array}$ \\
\hline Mengibaskan telinga & 12,00 & 5,00 \\
Mengibaskan ekor & 15,75 & 1,00 \\
Menggelengkan kepala & 1,00 & 1,75 \\
Menggetarkan kulit (reflex panniculus) & 2,00 & 1,25 \\
Menggoyangkan kaki & 0,25 & 0,00 \\
Berpindah tempat & 1,00 & 0,25 \\
Mengedipkan mata & 5,50 & 4,00 \\
Menggaruk dengan kaki & 0,50 & 0.25 \\
\hline
\end{tabular}

Tingginya frekuensi ekspresi perilaku pada posisi berdiri saat merumput apabila dibandingkan dengan posisi rebahan saat istirahat dimungkinkan karena perasaan tenang saat ruminasi. Aktivitas ruminasi merupakan salah satu indikator kesejahteraan seekor ruminansia (Napolitano et al., 2009). Demikian pula tidak ada aktivitas menggoyangkan kaki selama rebahan karena area kaki relatif lebih terlindung dari lalat saat kaki terlipat dan tertutup oleh badan (Gambar 2).

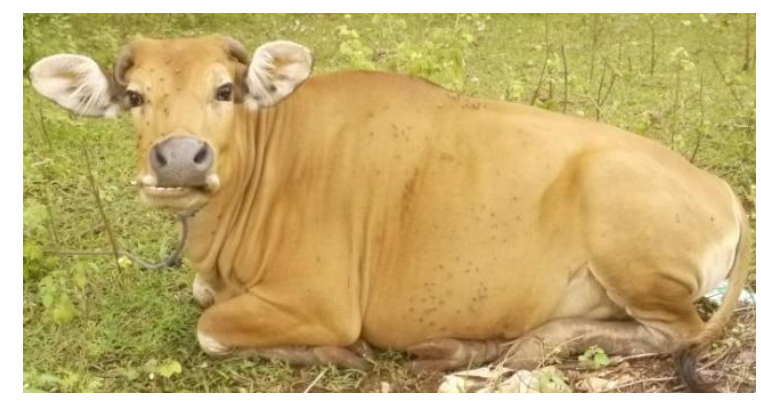

Gambar 2 Infestasi lalat penghisap darah dan lalat pengganggu pada saat sapi istirahat (ruminasi).
Perilaku yang diekspresikan oleh sapi akibat gangguan lalat mungkin dianggap sekedar mengusir lalat. Namun demikian gejala fly worry dapat sangat membahayakan bahkan hingga menimbulkan kecelakaan dan kematian ternak itu sendiri (Mauldin \& Peters-Kennedy, 2016). Perilaku menggaruk mata dapat menyebabkan trauma pada mata dan sekitarnya atau infeksi pada mata yang berujung pada kebutaan (Gambar 3).

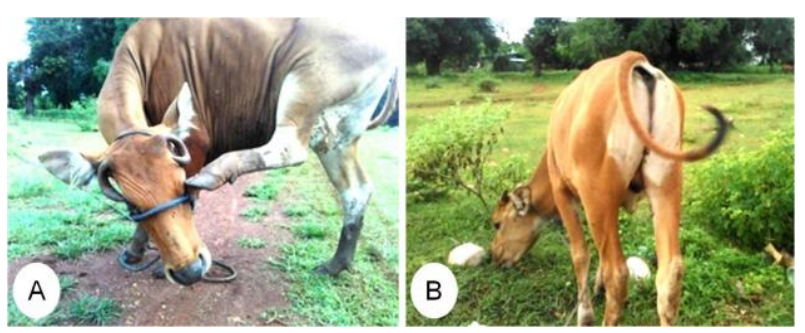

Gambar 3 Ekspresi perilaku sapi akibat gangguan lalat. (A) menggaruk mata dan (B) mengibaskan ekor.

\section{- SIMPULAN}

Dampak perubahan perilaku akibat infestasi lalat penghisap darah dan keberadaan lalat pengganggu pada sapi lebih terlihat saat merumput daripada saat istirahat.

\section{n INFORMASI PENULIS}

Penulis untuk Korespondensi

*AW: ajiwinarso@staf.undana.ac.id

Fakultas Kedokteran Hewan, Universitas Nusa Cendana, Kupang, Nusa Tenggara Timur, INDONESIA

\section{- UCAPAN TERIMA KASIH}

Penulis mengucapkan terima kasih kepada Kelompok Tani Ternak Sapi Desa Penfui Timur, Kecamatan Kupang Tengah, Kabupaten Kupang yang telah mengijinkan ternaknya digunakan dalam penelitian ini.

\section{- PUSTAKA ACUAN}

Hadi UK, Soviana S. 2010. Ektoparasit: Pengenalan, Identifikasi, dan Pengendaliannya. Bogor (ID): IPB Press.

Holdsworth PA, Vercruysse J, Rehbein S, Peter RJ, Bruin CD, Letonja T, Green P. 2006. World Association for the Advancement of Veterinary Parasitology (WAAVP) guidelines for evaluating the efficacy of ectoparasiticides against biting and nuisance flies on ruminants. Veterinary Parasitology, 136(1):3-13.

Mauldin EA, Peters-Kennedy J. 2016. Integumentary System. In: Jubb, Kennedy \& Palmer's Pathology of Domestic Animals: Volume 1. [online] Elsevier Health Sciences: pp.667.e1.

Napolitano F, Knierim U, Grass F, De Rosa G. 2009. Positive indicators of cattle welfare and their applicability to on-farm protocols, Italian Journal of Animal Science, 8(sup1): 355365 .

Zajac AM, Conboy GA. 2012. Veterinary Clinical Parasitology, 8th Ed. Oxford: Wiley-Blackwell. 